\title{
Cultivo de Gliricidia sepium e Leucaena leucocephala em alamedas visando a melhoria dos solos dos tabuleiros costeiros ${ }^{(1)}$
}

\begin{abstract}
Antônio Carlos Barreto(2) e Marcelo Ferreira Fernandes(2)
Resumo - O objetivo deste trabalho foi avaliar a biomassa da parte aérea de gliricídia (Gliricidia sepium) e leucena (Leucaena leucocephala) em cultivos em alameda, e o efeito da adição dessa biomassa sobre propriedades químicas e físicas de um Latossolo Amarelo dos tabuleiros costeiros de Sergipe. A produção de mandioca nas alamedas dessas leguminosas também foi determinada. A gliricídia foi plantada, em 1994, por estacas, e a leucena, em 1995, por mudas, utilizando-se o espaçamento de 3 x $1 \mathrm{~m}$, para ambas as espécies. Em intervalos de três a cinco meses, foram realizados cortes e incorporação do material ao solo. Caules com diâmetro superior a $1 \mathrm{~cm}$ foram desconsiderados na biomassa. A matéria seca desses cortes foi determinada anualmente, e em 1998 realizaram-se análises químicas e físicas do solo. Amostras de solo de área contígua foram utilizadas como controle. Foram produzidas, respectivamente, 4,87 e 5,80 t ha ${ }^{-1}$ ano $^{-1}$ de parte aérea, em média, por leucena e gliricídia. A gliricídia exerceu menor competição com a mandioca na entrelinha. Com a incorporação dessas leguminosas ao solo elevaram-se o $\mathrm{pH}$ e os teores de $\mathrm{Ca}+\mathrm{Mg}$, não sendo alteradas, porém, a matéria orgânica e a CTC. Também foi observada redução de densidade e elevação da macroporosidade em resposta à adição das leguminosas. Esses efeitos foram mais acentuados em menores profundidades.
\end{abstract}

Termos para indexação: consorciação, adubação verde, biomassa, fertilidade do solo.

\section{Use of Gliricidia sepium and Leucaena leucocephala in alley cropping systems to improve Brazilian coastal tableland soils}

\begin{abstract}
The objective of this study was to evaluate the shoot biomass of gliricidia (Gliricidia sepium) and leucaena (Leucaena leucocephala) in an alley cropping system and the addition effect of this biomass on the chemical and physical properties of a Yellow Latosol of a coastal tableland area, at Sergipe State, Brazil. The yield of cassava cultivated in the alleys of these legumes was also evaluated. Gliricidia was planted by cuttings in 1994, and leucaena was planted by seedlings in 1995, in rows of $3 \mathrm{~m}$ apart. At periods of three to five months, cuts were carried on and the shoot biomass was incorporated to the soil. Stems with diameter higher than $1 \mathrm{~cm}$ were not considered in the biomass weight. The dry matter obtained in these cuts was expressed in ton $\mathrm{ha}^{-1} \mathrm{year}^{-1}$. In 1998, soil samples were taken to quantify some soil chemical and physical properties. Soil samples from a neighbor area were used as control. Leucaena and gliricidia yield were, respectively, 4.87 and 5.80 ton ha $^{-1}$ year ${ }^{-1}$ of shoot dry matter. Gliricidia showed a lesser competition to cassava in the interrows. The incorporation of shoot biomass of both legumes to the soil caused an increment in the values of $\mathrm{pH}$ and $\mathrm{Ca}+\mathrm{Mg}$, but has not affected organic matter content and CEC. Decreases of the soil density and increases of the porosity were also observed in response to legume incorporation. These effects were most noticeable in the superficial layers.
\end{abstract}

Index terms: intercropping, green manures, biomass, soil fertility.

\footnotetext{
(1) Aceito para publicação em 19 de janeiro de 2001.

(2)Embrapa-Centro de Pesquisa Agropecuária dos Tabuleiros Costeiros, Caixa Postal 44, CEP 49001-970 Aracaju, SE.

E-mail:barreto@cpatc.embrapa.br

marcelo@cpatc.embrapa.br
}

\section{Introdução}

O cultivo dos solos com a retirada contínua da produção, sem a adoção de práticas que visem pelo menos a reposição de restos vegetais, promove, no 
decorrer do tempo, deterioração das suas características físicas, químicas e biológicas, e isto se verifica principalmente em decorrência de uma significativa redução dos teores de matéria orgânica. Em solos de textura arenosa a média e em regiões com predominância de temperatura e umidade elevadas, como é o caso dos tabuleiros costeiros (Haynes, 1970), esses efeitos são mais intensos em virtude das altas taxas de decomposição da matéria orgânica nessas condições (Alexander, 1977).

O manejo da matéria orgânica é essencial nessas circunstâncias, já que ela é a principal reserva de nitrogênio $(\mathrm{N})$ e responde por grande parte da capacidade de troca de cátions (CTC) do solo, estimada por Raij (1969), em 56 a 82\% nos solos tropicais. Portanto, a elevação do teor de carbono em solos desgastados permite a elevação da CTC, favorecendo a retenção de cátions e a conseqüente redução da sua lixiviação, como também o aumento na reserva de $\mathrm{N}$ e a melhoria da estrutura do solo (Igue, 1984).

Uma das alternativas propostas para amenizar esses problemas é a utilização da prática da adubação verde. Segundo o conceito atual, esta prática está associada a quatro pontos básicos nos diferentes sistemas agrícolas: cobertura e proteção do solo; manutenção ou melhoria das condições físicas, químicas e biológicas no solo; aração biológica e introdução de microvida em profundidade no solo e uso eventual da biomassa produzida para alimentação animal ou para outras finalidades (Calegari et al., 1993).

Um dos sistemas utilizados para adubação verde é o cultivo em alamedas (alley cropping), que consiste no plantio de leguminosas perenes, de porte arbustivo, em fileiras suficientemente espaçadas entre si, para permitir o plantio de culturas alimentares ou comerciais entre elas (Wilson \& Kang, 1981). O manejo desse sistema é feito por cortes periódicos da parte aérea das leguminosas, com utilização alternativa na alimentação animal ou para incorporação ao solo. O número de cortes realizados por ano depende da velocidade de rebrota das leguminosas, após cada corte, e da adequação às características das espécies semeadas nas entrelinhas. Essa semeadura nas entrelinhas ocorre no início das chuvas, ocasião em que é feita uma poda drástica da leguminosa, para retardar a rebrota e recomposição da copa e com isto atenuar seu efeito competitivo (Vearasilp, 1981; Carvalho Filho \& Languidey, 1988; Barreto \& Carvalho Filho, 1992).

Espera-se que, com a incorporação periódica de quantidades expressivas de biomassa das leguminosas nas entrelinhas, obtenham-se melhorias nas características químicas, físicas e biológicas dos solos, com conseqüente aumento do seu potencial produtivo, como vem sendo observado em alguns trabalhos com gliricídia nos ecossistemas dos tabuleiros costeiros da Bahia (Silva \& Mendonça, 1995), e com leucena, nos cerrados da região central do Brasil (Chagas et al., 1981, 1983).

O objetivo deste trabalho foi avaliar o efeito da incorporação da biomassa da parte aérea da gliricídia (Gliricidia sepium) e da leucena (Leucaena leucocephala), em cultivos em alameda, sobre algumas características químicas e físicas de um Latossolo Amarelo dos tabuleiros costeiros de Sergipe.

\section{Material e Métodos}

O estudo foi realizado no Campo Experimental "Antônio Martins", no Município de Lagarto, SE, em um solo Latossolo Amarelo. O clima da região se caracteriza por apresentar uma estação chuvosa, de março a agosto, e uma estação seca, de setembro a fevereiro. Foi plantada uma área com gliricídia e outra com leucena, variedade Cunningham, medindo, cada área, $1.800 \mathrm{~m}^{2}$, com fileiras de $40 \mathrm{~m}$ de comprimento. A gliricídia foi plantada em junho de 1994, com estacas de $30 \mathrm{~cm}$ de comprimento e $2,5 \mathrm{~cm}$ de diâmetro, em média, no espaçamento de $3 \mathrm{~m}$ entre linhas e $1 \mathrm{~m}$ entre covas, com duas estacas por cova. A leucena foi plantada em maio de 1995, na forma de mudas, no mesmo espaçamento. No plantio aplicaram-se $60 \mathrm{~kg} \mathrm{ha}^{-1}$ de $\mathrm{P}_{2} \mathrm{O}_{5}$ (superfosfato simples) e $30 \mathrm{~kg} \mathrm{ha}^{-1} \mathrm{de}$ $\mathrm{K}_{2} \mathrm{O}$ (cloreto de potássio), com aplicação lateral às estacas ou às mudas, a $10 \mathrm{~cm}$ de profundidade.

O primeiro corte das plantas foi feito um ano após o plantio, à altura de $50 \mathrm{~cm}$ da superfície do solo, e os cortes seguintes, a intervalos de três a cinco meses, em média. As plantas foram cortadas quando atingiram cerca de $2,5 \mathrm{~m}$ de altura. Na avaliação da produção de matéria seca, em cada época de corte, coletaram-se cinco amostras representativas em cada área, cada uma obtida em cinco metros lineares de sulco. Determinou-se a produção da parte aérea das plantas, à exceção dos caules lenhosos (diâmetro acima de $1 \mathrm{~cm}$ ). No corte realizado na gliricídia em novembro e na leucena 
em dezembro de 1997, coletou-se uma subamostra de cada uma das cinco amostras da parte aérea a ser incorporada ao solo, para a realização de análises de macronutrientes (Miyazawa., et al., 1999). Nos três primeiros cortes, avaliou-se a quantidade de matéria seca da vegetação nativa que se desenvolveu nas entrelinhas de leucena e de gliricídia. Nessa avaliação, considerou-se toda a biomassa contida em um quadriculado de madeira com área de $1 \mathrm{~m}^{2}$, em cinco locais amostrados ao acaso. Após as avaliações, realizou-se um corte de homogeneização nas plantas de toda a área, deixando-as sobre a superfície do solo entre os sulcos. O material podado foi deixado sobre a superfície do solo até sua secagem e desprendimento das folhas e galhos tenros. Os caules lenhosos foram retirados da área, para não dificultar a gradagem a realizar-se em seguida, e o material vegetal foi incorporado. No último corte de cada ano, que em geral coincide com a estação seca, a biomassa produzida não foi incorporada, e foi deixada sobre a superfície do solo, evitando-se o revolvimento do solo, e, conseqüentemente, a perda de sua umidade.

Em 1996, utilizaram-se cinco entrelinhas de $40 \mathrm{~m}$ de comprimento de leucena e de gliricídia, plantando-se duas fileiras de mandioca com espaçamento de 1,0 m entre linhas e densidade de 1,0 m entre covas. Em outra parte das áreas, as fileiras de leucena e de gliricídia não foram consorciadas com a mandioca. Plantou-se, também, a mandioca, em cultivo isolado, com o mesmo espaçamento e densidade. Avaliou-se a produção de raízes de mandioca, em quatro amostras representativas, coletadas ao acaso, em cada sistema, constituídas pelas plantas contidas em $10 \mathrm{~m}$ lineares de sulco. O delineamento usado foi o inteiramente casualizado, com quatro repetições (amostras). Os dados obtidos foram submetidos à análise de variância e as médias comparadas pelo teste de Tukey a $5 \%$ de probabilidade.

Em maio de 1998, foram coletadas amostras deformadas e indeformadas de solo, para análises químicas $(\mathrm{pH}$, $\mathrm{MO}, \mathrm{Ca}+\mathrm{Mg}$ e CTC) e físicas (densidade, macroporosidade, microporosidade e porosidade total), conforme Embrapa (1997). As amostras foram coletadas ao acaso em cinco pontos, nas entrelinhas das áreas de gliricídia e de leucena que não foram cultivadas com mandioca, e em uma área contígua, com vegetação nativa, considerada como tratamento-testemunha. As amostras deformadas foram coletadas nas profundidades de 0-5, 5-10 e 10-20 cm, e as indeformadas, nas de 0-15 e $15-30 \mathrm{~cm}$.

O delineamento experimental usado foi o inteiramente casualizado, com parcelas subdivididas (tratamentos em parcelas e profundidades em subparcelas), e cinco repetições (amostras), sendo as médias comparadas pelo teste de Tukey a $5 \%$ de probabilidade.

\section{Resultados e Discussão}

Após os cortes das plantas de gliricídia e de leucena, verificou-se rebrota em ambas as espécies. A produtividade média anual de matéria seca da parte aérea de plantas de gliricídia após quatro anos de cultivo foi superior à das plantas de leucena, em três anos (Tabela 1). No início do ano de 1997, houve incidência do fungo Camptomeris leucaenae, que provocou a queda de parte da folhagem de leucena durante alguns meses. Como esse material não foi avaliado, a produção de matéria seca nesse período pode ter sido subestimada. Isto resultou em um intervalo de sete meses entre o terceiro e o quarto cortes. Em solos de tabuleiro do Sul da Bahia, Silva \& Mendonça (1995) verificaram um melhor desempenho da gliricídia em relação ao da leucena. No entanto, em condições mais adversas, como as do Oeste da África, Atta-Krah \& Sumberg (1988)

Tabela 1. Matéria seca da parte aérea $\left(t \mathrm{ha}^{-1}\right)$ das plantas de gliricídia e leucena em cortes periódicos a partir de um ano após o plantio. Lagarto, $\mathrm{SE}^{(1)}$.

\begin{tabular}{clcc}
\hline Ano & Mês & Gliricídia & Leucena \\
\hline \multirow{2}{*}{1995} & Jul. & 2,72 & - \\
& Dez. & 3,15 & - \\
\hline Total & & 5,87 & - \\
\hline \multirow{2}{*}{1996} & Maio & 1,84 & 2,92 \\
& Ago. & 1,52 & 1,16 \\
& Nov. & - & 1,25 \\
& Dez. & 1,84 & - \\
\hline Total & & 5,20 & 5,33 \\
\hline 1997 & Abr. & 2,44 & - \\
& Jun. & - & 1,43 \\
& Jul. & 1,93 & - \\
& Set. & - & 1,54 \\
& Nov. & 2,51 & - \\
& Dez. & - & 1,53 \\
\hline Total & & 6,88 & 4,50 \\
\hline 1998 & Abr. & 1,65 & 2,32 \\
& Nov. & 3,59 & 2,46 \\
\hline Total & & 5,24 & 4,78 \\
\hline Média & & 5,80 & 4,87 \\
anual & & &
\end{tabular}

(1)Plantio de gliricídia e leucena em junho de 1994 e julho de 1995, respectivamente. 
relataram produção de matéria seca superior da leucena em relação à da gliricídia.

$\mathrm{Na}$ gliricídia foram observados teores mais elevados de $\mathrm{K}, \mathrm{Ca}, \mathrm{Mg}$ e $\mathrm{S}$, enquanto os de $\mathrm{N}$ e $\mathrm{P}$ foram praticamente os mesmos em ambas as espécies (Tabela 2). Considerando apenas o $\mathrm{N}$, com a incorporação da biomassa da gliricídia e da leucena, seriam adicionados ao solo, em média, cerca de 160 e $130 \mathrm{~kg} \mathrm{ha}^{-1} \mathrm{ano}^{-1}$ de $\mathrm{N}$, respectivamente.

Portanto, nos tabuleiros costeiros as duas leguminosas atenderiam aos requerimentos em alta produtividade de biomassa e riqueza nutricional, citados por Gutteridge \& Shelton (1993), como desejáveis para o cultivo em alamedas.

Quanto à capacidade de convivência dessas leguminosas com as culturas plantadas nas entrelinhas, o nível de competição entre elas dependerá do comportamento vegetativo da leguminosa, associado a algumas práticas de manejo. Na leucena observa-se uma rebrota um pouco mais rápida do que na gliricídia, sendo formada uma copa rala, com galhos lenhosos e longos. Na gliricídia, após a primeira poda, tem-se uma copa compacta e galhos menos lenhosos e mais curtos.

Tabela 2. Teores médios de macronutrientes na parte aérea da gliricídia (nov./1997) e leucena (dez./97), e acúmulo de nutrientes pela biomassa. Lagarto, SE.

\begin{tabular}{lcccccc}
\hline Espécie & $\mathrm{N}$ & $\mathrm{P}$ & $\mathrm{K}$ & $\mathrm{Ca}$ & $\mathrm{Mg}$ & $\mathrm{S}$ \\
\hline Gliricídia & 27,3 & 1,7 & 15,6 & 10,7 & 6,6 & 2,9 \\
Leucena & 26,9 & 1,7 & 10,9 & 3,2 & 3,5 & 1,4 \\
\hline \multicolumn{7}{c}{ Biomassa $\left(\mathrm{t} \mathrm{ha}^{-1}\right)$} \\
Gliricídia & 0,63 & 0,04 & 0,36 & 0,25 & 0,15 & 0,07 \\
Leucena & 0,39 & 0,02 & 0,16 & 0,05 & 0,05 & 0,02 \\
\hline
\end{tabular}

A proporção de caules lenhosos na matéria seca da parte aérea da leucena é superior à da gliricídia, mas a de folhas é inferior a esta (Tabela 3). A leucena é uma espécie que exerce forte competição sobre as culturas plantadas nas entrelinhas (Atta-Krah \& Sumberg, 1988; Schroth \& Zech, 1995). De fato, a leucena teve maior efeito competitivo quando comparada com a gliricídia. Outra evidência do maior efeito competitivo da leucena foi a produção da vegetação nativa nas suas entrelinhas, que foi nitidamente inferior à observada junto à gliricídia.

No cultivo isolado de mandioca em 1996, a produção de raízes foi estatisticamente superior à obtida tanto no consórcio com a gliricídia quanto com a leucena (Tabela 4).

A competição tornou-se mais crítica em função do espaçamento utilizado ( $3 \mathrm{~m}$ entre as fileiras), já que não foram feitos cortes complementares visando atenuar esse efeito. Segundo Karim et al. (1993), em alamedas de gliricídia e de guandu, com 2 a $4 \mathrm{~m}$ de largura, obtiveram-se maiores produções de milho cultivado nas entrelinhas do que em espaçamentos maiores. Provavelmente, isto se deveu à incorporação de maiores quantidades de matéria seca ao solo. No entanto, os autores ressaltam uma maior necessidade de trabalho manual nas freqüentes operações de cortes e de distribuição da folhagem sobre o solo, nos menores espaçamentos. Chagas et al. (1981), trabalhando com a leucena, nos espaçamentos de 4 e $5 \mathrm{~m}$ nas entrelinhas, não observaram as limitações de sombreamento relatadas nos espaçamentos de $2 \mathrm{e}$ $3 \mathrm{~m}$ entre as fileiras. Korwar (1998), utilizando espaçamento de 7,8 m entre fileiras de leucena, ob-

Tabela 3. Matéria verde e seca dos componentes da parte aérea da gliricídia (média de três primeiros cortes) e leucena (primeiro corte), e matéria seca da vegetação nativa. Lagarto, $\mathrm{SE}^{(1)}$.

\begin{tabular}{|c|c|c|c|c|c|c|c|c|c|}
\hline \multirow[t]{3}{*}{ Espécie } & \multirow[t]{3}{*}{ Matéria } & \multicolumn{5}{|c|}{ Parte aérea } & \multirow[t]{3}{*}{$\mathrm{VN}$} & \multirow[t]{3}{*}{$\mathrm{F} / \mathrm{PA}$} & \multirow[t]{2}{*}{$\mathrm{CL} / \mathrm{PA}$} \\
\hline & & CL & GT & $\mathrm{F}$ & Total & $\mathrm{GT}+\mathrm{F}$ & & & \\
\hline & & --------. & ------. & ------. & $\left.h^{-1}\right)$ & --- & & & -----. \\
\hline \multirow[t]{2}{*}{ Gliricídia } & Verde & 3,49 & 2,56 & 8,41 & 14,46 & 10,97 & - & 58,2 & 24,1 \\
\hline & Seca & 1,13 & 0,50 & 2,18 & 3,81 & 2,68 & 2,73 & 57,2 & 29,6 \\
\hline \multirow[t]{2}{*}{ Leucena } & Verde & 4,50 & 3,37 & 5,75 & 13,62 & 9,12 & - & 42,2 & 33,0 \\
\hline & Seca & 1,70 & 1,11 & 1,72 & 4,53 & 2,83 & 0,59 & 38,0 & 37,5 \\
\hline
\end{tabular}

${ }^{(1)} \mathrm{CL}$ : caules lenhosos; GT: galhos tenros; F: folhas; PA: parte aérea; VN: vegetação nativa nas entrelinhas de gliricídia e leucena. 
teve produções de sorgo correspondentes a $94 \%$ em relação ao cultivo isolado, embora fossem ocupados $86 \%$ da área no sistema.

Tanto com a incorporação da biomassa de gliricídia, em cortes sucessivos durante três anos, quanto da leucena durante dois anos, não se observaram aumentos significativos nos teores de matéria orgânica e nos valores da CTC, em relação à testemunha, independentemente da profundidade amostrada, apesar de se observar uma tendência de

Tabela 4. Peso das raízes de mandioca, e matéria seca das plantas de gliricídia e leucena (um corte), em cultivo isolado e em consórcio. Lagarto, SE, 1996 ${ }^{(1)}$.

\begin{tabular}{lccc}
\hline Sistema de produção & \multirow{2}{*}{$\begin{array}{c}\text { Peso de raiz de } \\
\text { mandioca }\end{array}$} & \multicolumn{2}{c}{ Matéria seca } \\
\cline { 3 - 4 } & & Gliricídia & Leucena \\
\hline Cultivo isolado & $35,9 \mathrm{a}$ & $1,42 \mathrm{a}$ & $1,07 \mathrm{a}$ \\
Gliricídia x mandioca & $13,9 \mathrm{~b}$ & $1,95 \mathrm{a}$ & - \\
Leucena x mandioca & $8,2 \mathrm{c}$ & - & $1,29 \mathrm{a}$ \\
\hline
\end{tabular}

${ }^{(1)}$ Médias seguidas pelas mesmas letras minúsculas nas colunas não diferem entre si pelo teste de Tukey a $5 \%$ de probabilidade.

Tabela 5. Características químicas de amostras do Latossolo Amarelo coletadas em áreas-testemunha, com gliricídia e com leucena em três profundidades. Lagarto, SE, $1998^{(1)}$.

\begin{tabular}{|c|c|c|c|c|}
\hline \multirow[t]{2}{*}{ Tratamento } & \multirow[t]{2}{*}{$\mathrm{pH}\left(\mathrm{H}_{2} \mathrm{O}\right)$} & MO & $\mathrm{Ca}+\mathrm{Mg}$ & CTC \\
\hline & & $(\%)$ & \multicolumn{2}{|c|}{$\left(\mathrm{cmol}_{\mathrm{c}} \mathrm{dm}^{-3}\right)$} \\
\hline & \multicolumn{4}{|c|}{$0-5 \mathrm{~cm}$} \\
\hline Testemunha & $5,36 \mathrm{~b}$ & $2,69 \mathrm{a}$ & $0,72 b$ & $3,26 \mathrm{a}$ \\
\hline Gliricídia & $5,76 \mathrm{ab}$ & $3,42 \mathrm{a}$ & $1,32 \mathrm{a}$ & $3,72 \mathrm{a}$ \\
\hline \multirow[t]{2}{*}{ Leucena } & $6,12 \mathrm{a}$ & $2,99 \mathrm{a}$ & $1,39 \mathrm{a}$ & $3,64 \mathrm{a}$ \\
\hline & \multicolumn{4}{|c|}{$5-10 \mathrm{~cm}$} \\
\hline Testemunha & $4,99 \mathrm{~b}$ & $2,29 \mathrm{a}$ & $0,43 b$ & $3,27 \mathrm{a}$ \\
\hline Gliricídia & $5,30 \mathrm{ab}$ & $3,08 \mathrm{a}$ & $0,94 \mathrm{a}$ & $3,35 \mathrm{a}$ \\
\hline \multirow[t]{2}{*}{ Leucena } & $5,76 \mathrm{a}$ & $2,34 \mathrm{a}$ & $1,15 \mathrm{a}$ & $3,20 \mathrm{a}$ \\
\hline & \multicolumn{4}{|c|}{$10-20 \mathrm{~cm}$} \\
\hline Testemunha & $4,80 \mathrm{~b}$ & $2,21 \mathrm{a}$ & $0,25 b$ & $2,82 \mathrm{a}$ \\
\hline Gliricídia & $4,87 \mathrm{~b}$ & $2,09 \mathrm{a}$ & $0,52 \mathrm{ab}$ & $3,36 \mathrm{a}$ \\
\hline Leucena & $5,55 \mathrm{a}$ & $1,91 \mathrm{a}$ & $0,86 \mathrm{a}$ & $3,05 \mathrm{a}$ \\
\hline Média geral & 5,39 & 2,56 & 0,84 & 3,30 \\
\hline $\mathrm{CV}(\%)(\mathrm{a})$ & 4,98 & 18,79 & 34,47 & 12,19 \\
\hline $\mathrm{CV}(\%)(\mathrm{b})$ & 4,19 & 17,75 & 17,87 & 13,78 \\
\hline
\end{tabular}

(1) Na mesma profundidade, médias seguidas pelas mesmas letras nas colunas não diferem entre si pelo teste de Tukey a $5 \%$ de probabilidade. aumento no valor destes parâmetros, principalmente a $0-5 \mathrm{~cm}$ e a $5-10 \mathrm{~cm}$ (Tabela 5). É possível que, com o revolvimento do solo, como parte do manejo na incorporação do material, tenha sido favorecida a sua decomposição, e não tenha ocorrido um maior acúmulo de $\mathrm{C}$, pelo menos durante o período considerado. Testa et al. (1992), estudando o efeito de sucessões de culturas com produções de biomassa superiores às da vegetação espontânea, verificaram elevação do teor de C do solo, desde que cultivado sem revolvimento do solo.

Os teores de $\mathrm{Ca}+\mathrm{Mg}$, e, conseqüentemente, os valores de $\mathrm{pH}$, nos sistemas com gliricídia e leucena, foram superiores aos da testemunha; mas apenas os da área com leucena foram estatisticamente diferentes dos da testemunha, em qualquer profundidade (Tabela 5). Apesar dos menores teores de $\mathrm{Ca}$ e $\mathrm{Mg}$ na biomassa de leucena e da menor quantidade incorporada em virtude da menor produção e do menor período de incorporação (Tabela 2), os resultados foram, em média, equivalentes ao da gliricídia.

A incorporação, principalmente de gliricídia, causou significativo decréscimo nos valores da densidade, e aumento da porosidade do solo, em relação à testemunha, na profundidade de $0-15 \mathrm{~cm}$ (Tabela 6), o que está de acordo com resultados de Silva \& Mendonça (1995) e Mapa \& Gunasena (1995). Os valores da porosidade total foram acrescidos em função apenas do aumento na macroporosidade. Também se verificou diminuição significativa dos valores de densidade com a incorporação de gliricídia na profundidade de $15-30 \mathrm{~cm}$, e o efeito sobre a macroporosidade, apesar de não-significativo, já se manifesta. $\mathrm{O}$ decréscimo dos valores da densidade e o aumento da macroporosidade podem estar relacionados ao aumento, apesar de não-significativo, do teor de matéria orgânica (Tabela 5). Mapa \& Gunasena (1995) deram destaque a essa relação ao avaliarem o uso da gliricídia e do guandu em cultivo em alamedas. Esses autores relacionaram o aumento no teor de matéria orgânica ao aumento na estabilidade de agregados e porosidade, sendo favorecida a infiltração da água no solo e reduzido o escorrimento superficial. Se esses efeitos ocorrerem em um prazo

Pesq. agropec. bras., Brasília, v. 36, n. 10, p. 1287-1293, out. 2001 
Tabela 6. Características físicas de amostras de solo Latossolo Amarelo coletadas em áreas-testemunha, com gliricídia e com leucena, em duas profundidades. Lagarto, SE, $1998^{(1)}$.

\begin{tabular}{|c|c|c|c|c|}
\hline Tratamento & $\begin{array}{l}\text { Densidade do solo } \\
\qquad\left(\mathrm{kg} \mathrm{dm}^{-3}\right)\end{array}$ & Macroporosidade & $\begin{array}{l}\text { Microporosidade } \\
(\%) \text { - }\end{array}$ & Porosidade total \\
\hline & \multicolumn{4}{|c|}{$0-15 \mathrm{~cm}$} \\
\hline Testemunha & $1,80 \mathrm{a}$ & $6,95 b$ & $24,33 \mathrm{a}$ & $31,28 b$ \\
\hline Gliricídia & $1,54 \mathrm{c}$ & $21,00 \mathrm{a}$ & $22,19 a$ & $43,16 a$ \\
\hline \multirow[t]{2}{*}{ Leucena } & $1,68 b$ & $15,70 \mathrm{a}$ & $20,24 a$ & $35,94 \mathrm{~b}$ \\
\hline & \multicolumn{4}{|c|}{$15-30 \mathrm{~cm}$} \\
\hline Testemunha & $1,84 \mathrm{a}$ & $8,43 \mathrm{a}$ & $22,47 \mathrm{a}$ & $30,90 \mathrm{a}$ \\
\hline Gliricídia & $1,71 \mathrm{~b}$ & $14,32 \mathrm{a}$ & $21,37 \mathrm{a}$ & $35,69 a$ \\
\hline Leucena & $1,78 \mathrm{ab}$ & $10,16 \mathrm{a}$ & $22,22 \mathrm{a}$ & $32,38 \mathrm{a}$ \\
\hline Média geral & 1,72 & 12,76 & 22,13 & 34,89 \\
\hline CV (\%) (a) & 2,62 & 22,99 & 10,36 & 5,05 \\
\hline CV (\%) (b) & 3,09 & 32,32 & 8,79 & 8,72 \\
\hline
\end{tabular}

${ }^{(1)} \mathrm{Na}$ mesma profundidade, médias seguidas pelas mesmas letras nas colunas não diferem entre si pelo teste de Tukey a 5\% de probabilidade.

mais longo e em maior profundidade, como se espera, podem ser aventadas melhorias na estrutura coesa das camadas subsuperficiais dos solos dos tabuleiros, geralmente encontradas entre 20 e $60 \mathrm{~cm}$ de profundidade, segundo Jacomine \& Ribeiro (1997).

\section{Conclusões}

1. O cultivo da gliricídia e da leucena é viável nos tabuleiros costeiros.

2. A utilização da gliricídia em sistema de cultivo em alamedas em tabuleiros costeiros é viável, visto que o seu porte vegetativo é mais compacto, e é exercida menor competição com a cultura plantada nas entrelinhas.

3. A incorporação da biomassa da gliricídia e da leucena em solos de tabuleiros costeiros promove melhorias em características químicas $(\mathrm{Ca}+\mathrm{Mg}$ e $\mathrm{pH})$ e físicas (densidade e macroporosidade), principalmente nas menores profundidades.

\section{Referências}

ALEXANDER, M. Organic matter decomposition. In: ALEXANDER, M. Introduction to soil microbiology. New York: J. Willey, 1977. p. 128-147.

ATTA-KRAH, A. N.; SUMBERG, J. E. Studies with Gliricidia sepium for crop/livestock production systems in West Africa. Agroforestry Systems, Dordrecht, v. 6, p. $97-118,1988$.

BARRETO, A. C.; CARVALHO FILHO, O. M. Cultivo de leucena em consórcio com feijão, milho e algodão. Pesquisa Agropecuária Brasileira, Brasília, v. 27, n. 11, p. 1533-1540, nov. 1992.

CALEGARI, A.; MONDARDO, A.; BULISANI, E. A.; WILDNER, L. do P.; COSTA, M. B. B. da; ALCÂNTARA, P. B.; MIYASAKA, S.; AMADO, T. J. C. Adubação verde no sul do Brasil. 2. ed. Rio de Janeiro: Assessoria e Serviços a Projetos em Agricultura Alternativa, 1993. $346 \mathrm{p}$.

CARVALHO FILHO, O. M. de; LANGUIDEY, P. H. Leucena versus farelo de coco como suplemento para vacas em lactação mantidas a pasto. Pesquisa Agropecuária Brasileira, Brasília, v. 23, n. 10, p. 1181-1187, out. 1988.

CHAGAS, J. M.; KLUTHCOUSKI, J.; AQUINO, A. R. L. de. Leucaena leucocephala como adubo verde para a cultura de feijão em cerrado. Pesquisa Agropecuária Brasileira, Brasília, v. 16, n. 6, p. 809-814, jun. 1981.

CHAGAS, J. M.; PEREIRA FILHO, I. A.; VIEIRA, C. Efeitos da leucena e da adubação NPK sobre a cultura do feijão no cerrado. Revista Ceres, Viçosa, MG, v. 30, n. 172, p. 481-485, 1983.

EMBRAPA. Centro Nacional de Pesquisa de Solos (Rio de Janeiro, RJ). Manual de métodos de análises de solo. 2. ed. Rio de Janeiro, 1997. 212 p. 
GUTTERIDGE, R. C.; SHELTON, H. M. The scope and potential of tree legumes in agroforestry. Agroforestry Systems, Dordrecht, v. 23, p. 177-194, 1993.

HAYNES, J. L. Uso agrícola dos tabuleiros costeiros do Nordeste do Brasil: um exame das pesquisas. 2. ed. Recife: Sudene, 1970. 139 p.

IGUE, K. Dinâmica da matéria orgânica e seus efeitos nas propriedades do solo. In: FUNDAÇÂO CARGILL (Campinas, SP). Adubação verde no Brasil. Campinas: Fundação Cargill, 1984. p. 232-267.

JACOMINE, P. K. I.; RIBEIRO, M. R. Solos coesos dos tabuleiros costeiros: características, distribuição geográfica, gênese e manejo. In: CONGRESSO BRASILEIRO DE CIÊNCIA DO SOLO, 26., 1997, Rio de Janeiro. Anais... Rio de Janeiro: Sociedade Brasileira de Ciência do Solo, 1997. 1 CD-ROM.

KARIM, A. B.; SAVILL, P. S.; RHODES, E. R. The effects of between-row (alley widths) and within-row spacings of Gliricidia sepium on alley-cropped maize in Sierra Leone. Agroforestry Systems, Dordrecht, v. 24, p. 81-93, 1993.

KORWAR, G. R. Fodder production potential of leucaena hedgerows on an Alfisol and a Vertisol in the semi-arid tropics. In: INTERNATIONAL WORKSHOP ON NITROGEN FIXING TREES FOR FODDER PRODUCTION, 1998, Morrilton. Proceedings... Morrilton: Winrock International, 1998. p. 146-153.

MAPA, R. B.; GUNASENA, H. P. M. Effect of alley cropping on soil aggregate stability of a tropical Alfisol. Agroforestry Systems, Dordrecht, v. 32, p. 237-245, 1995.
MIYAZAWA, M.; PAVAN, M. A.; MURAOKA, T.; CARMO, C. A. F. S.; MELLO, W. J. Análises químicas de tecido vegetal. In: SILVA, F. C. (Org.). Manual de análises químicas de solos, plantas e fertilizantes. Brasília: Embrapa-SPI, 1999. p. 171-223.

RAIJ, B. van. A capacidade de troca de cátions das frações orgânica e mineral dos solos. Bragantia, Campinas, v. 28, n. 8 , p. 85-112, 1969.

SCHROTH, G.; ZECH, W. Above and below-ground biomass dynamics in a sole cropping and an alley cropping system with Gliricidia sepium in the semi-deciduous rainforest zone of West Africa. Agroforestry Systems, Dordrecht, v. 31, p. 181-198, 1995.

SILVA, L. F. da; MENDONÇA, J. R. Comportamento da gliricídia (G. sepium) em solos de tabuleiro do Sul da Bahia. Ilhéus: Ceplac/Centro de Pesquisa do Cacau, 1995. $15 \mathrm{p}$.

TESTA, V. M.; TEIXEIRA, L. A. J.; MIELNICZUK, J. Características químicas de um Podzólico Vermelho-Escuro afetadas por sistemas de culturas. Revista Brasileira de Ciência do Solo, Campinas, v. 16, p. 107-114, 1992.

VEARASILP, T. Digestibility of rice straw rations supplemented with Leucaena leucocephala and Gliricidia maculata. Thailand Journal of Agriculture Science, Chiang Mai, v. 14, p. 259-264, 1981.

WILSON, G. F.; KANG, B. T. Developing stable and productive biological cropping systems for the humid tropics. In: STONEHOUSE, B. (Ed.). Biological husbandry: a scientific approach to organic farming. London: Butterworths, 1981. p. 193-203. 